\title{
Interocular Suppression in Primary Visual Cortex in Strabismus
}

\author{
${ }^{\circledR}$ John R. Economides, ${ }^{-}$Daniel L. Adams, and ${ }^{\circledR}$ Jonathan C. Horton \\ Program in Neuroscience, Department of Ophthalmology, University of California, San Francisco, California 94143
}

People with strabismus acquired during childhood do not experience diplopia (double vision). To investigate how perception of the duplicate image is suppressed, we raised two male monkeys with alternating exotropia by disinserting the medial rectus muscle in each eye at age four weeks. Once the animals were mature, they were brought to the laboratory and trained to fixate a small spot while recordings were made in primary visual cortex (V1). Drifting gratings were presented to the receptive fields of 500 single neurons for eight interleaved conditions: (1) right eye monocular; (2) left eye monocular; (3) right eye's field, right eye fixating; (4) right eye's field, left eye fixating; (5) left eye's field, right eye fixating; (6) left eye's field, left eye fixating; (7) both eyes' fields, right eye fixating; (8) both eyes' fields, left eye fixating. As expected, ocular dominance histograms showed a monocular bias compared with normal animals, but many cells could still be driven via both eyes. Overall, neuronal responses were not affected by switches in ocular fixation. Individual neurons exhibited binocular interactions, but mean population indices indicated no net interocular suppression or facilitation. Even neurons located in cortex with reduced cytochrome oxidase (CO) activity, representing portions of the nasal visual field where perception is suppressed during binocular viewing, showed no net inhibition. These data indicate that V1 neurons do not appear to reflect strabismic suppression and therefore the elimination of diplopia is likely to be mediated at a higher cortical level.

Key words: exotropia; visual suppression; anomalous retinal correspondence; stereopsis; diplopia; suppression scotoma

Significance Statement

In patients with strabismus, images fall on non-corresponding points in the two retinas. Only one image is perceived, because signals emanating from the other eye that convey the duplicate image are suppressed. The benefit is that diplopia is prevented, but the penalty is that the visual feedback required to adjust eye muscle tone to realign the globes is eliminated. Here, we report the first electrophysiological recordings from the primary visual cortex (V1) in awake monkeys raised with strabismus. The experiments were designed to reveal how perception of double images is avoided.

\section{Introduction}

Misalignment of the eyes gives rise to diplopia because images fall on non-corresponding loci in the two retinas (von Gräfe, 1854). Visual suppression averts diplopia, but also breaks the feedback loop that normally would prompt adjustment of extraocular muscle tone to restore ocular alignment (Tychsen, 1992). Consequently, suppression allows strabismus to persist, and in some cases leads to amblyopia (Hallum et al., 2017). We have

\footnotetext{
Received Jan. 8, 2021; revised Apr. 22, 2021; accepted Apr. 27, 2021.

Author contributions: J.R.E., D.L.A., and J.C.H. designed research; J.R.E., D.L.A., and J.C.H. performed research; J.R.E., D.L.A., and J.C.H. analyzed data; J.R.E., D.L.A., and J.C.H. wrote the paper.

This work was supported by National Eye Institute Grants EY029703 (to J.C.H.) and EY02162 (Vision Core Grant) and by an unrestricted grant from Research to Prevent Blindness. The California National Primate Research Center is supported by a Base Grant from the NIH Office of the Director OD011107. Jessica Wong and Jimmy Pham provided computer programming. Mikayla Dilbeck, Brittany Rapone, and Joshua Simmons assisted with experiments.

The authors declare no competing financial interests.

Correspondence should be addressed to Jonathan C. Horton at Jonathan.Horton@ucsf.edu.

https://doi.org/10.1523/JNEUROSCI.0044-21.2021

Copyright $\odot 2021$ the authors
}

investigated the responses of single cells to binocular stimulation in striate cortex of awake, strabismic macaques in the hope of uncovering the neural mechanism of visual suppression.

In exotropia, an outwards deviation of the eyes, an image that falls on the fovea in one eye lands on the temporal retina in the other eye at a site known as the diplopia point (Fig. 1A). Perception of the diplopia point is robustly suppressed to avoid double vision (Hatt et al., 2009). Although textbooks typically describe the single diplopia point aligned with the fovea, in fact wherever the visual fields overlap the signals from one retina must be inhibited in favor of the other retina at some level in the visual system. Perception from a large expanse of temporal retina is suppressed in favor of nasal retina in the other eye. In this sense, there are myriad diplopia points, each matching a retinal locus that is perceived via the fellow eye. The aggregation of diplopia points gives rise to a suppression scotoma in each eye's nasal visual field where perception is blocked, but only during binocular viewing (Fig. 1B) (Das, 2016). It is worth noting that spatial resolution at the diplopia point (if perception were not suppressed) is always lower than at the matching locus that is perceived in the other eye. 
A

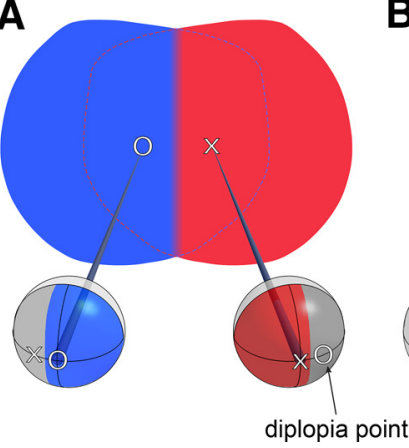

B

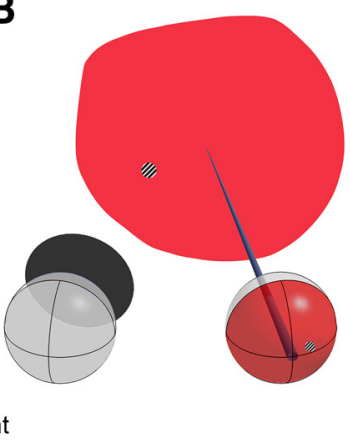

C

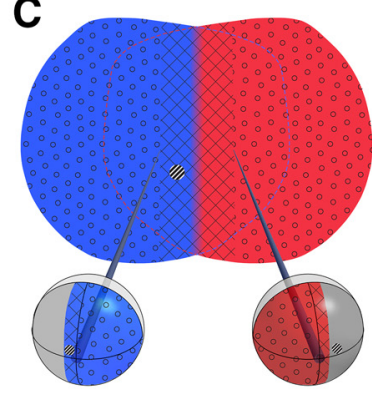

anesthetized animals are also problematic because strabismic suppression is a phenomenon that may occur only in conscious subjects. For these reasons, we have taken the approach of recording in awake, strabismic animals.

\section{Materials and Methods}

\section{Experimental design}

An alternating exotropia was generated in two male rhesus monkeys by tenotomy of the medial rectus muscle in each eye at age four weeks (Economides et al., 2007). The muscles reattached spontaneously to the globe, with partial restoration of adduction, but persistence of strabismus (Adams et al., 2018). The animals were raised at the California National Primate Research Center and transferred to our laboratory at age three years.

A titanium headpost and recording chamber were implanted (Adams et al., $2007,2011)$. The chamber had a $19 \mathrm{~mm}$ internal diameter and was centered $12 \mathrm{~mm}$ from the midline over the right V1 in each

In exotropia, different portions of the visual scene impinge on corresponding loci in the two retinas, potentially giving rise to visual confusion. For example, one image falls on the left fovea while a separate image lands on the right fovea (Fig. $1 A$ ). This perceptual dilemma is resolved by shifting the spatial localization of one retina with respect to the other, a phenomenon known as anomalous retinal correspondence (Wong et al., 2000).

A clue to the mechanism of visual suppression has come from histochemical studies of the mitochondrial enzyme, cytochrome oxidase (CO). In strabismic monkeys a novel pattern of alternating pale and dark $\mathrm{CO}$ stripes is present in striate cortex (Tychsen and Burkhalter, 1997; Horton et al., 1999; Fenstemaker et al., 2001). In exotropia, CO activity in each hemisphere is reduced in the ocular dominance columns supplied by the ipsilateral eye's peripheral temporal retina (Adams et al., 2013). This pattern of reduced cortical metabolism matches the location of nasal suppression scotomas in the visual field of each eye mapped in humans with exotropia (Cooper and Record, 1986; Herzau, 1996; Joosse et al., 1999; Economides et al., 2012). This correspondence suggests that diplopia is avoided by suppression of neural activity driven by each temporal retina. The present study explores this hypothesis through single cell recordings in striate cortex.

Previous investigators have searched for interocular suppression in strabismic animals under anesthesia by recording neurons in the primary visual cortex (V1) and comparing responses to stimulation of the receptive field in one eye or both eyes (Sengpiel and Blakemore, 1994; Sengpiel et al., 1994; Smith et al., 1997; Zhang et al., 2005; Sengpiel et al., 2006). Display of the same stimulus to corresponding retinal loci does not accurately replicate the conditions that arise in strabismus. One must stimulate non-corresponding retinal loci, displaced by the magnitude of the ocular deviation (Fig. $1 C$ ). This response must be compared with the response generated with the fellow eye occluded to address the potential impact of strabismic suppression (Fig. $1 B)$. This is difficult to accomplish in anesthetized animals, because the deviation angle (horizontal, vertical, and torsional) differs from that present in the awake state. Experiments in animal. It was positioned as far posterior as the nuchal ridge would permit, with one footplate bent sharply to cross the lambdoid suture. Accurate placement over striate cortex was confirmed by drying the dura after bone removal, rendering it semi-transparent. The lunate sulcus, a landmark marking the edge of the operculum, was visible a few millimeters from the anterior wall of the chamber. All surgical and experimental procedures were approved by the Institutional Animal Care and Use Committee at the University of California San Francisco (UCSF). Buprenorphine was administered for analgesia for at least $2 \mathrm{~d}$ after surgery.

Testing in each monkey was performed with optical correction for distance, determined by cycloplegic refraction. Monkey 1 had an exotropia of $15-20^{\circ}$. There was a $2-3 \mathrm{~Hz}$ vertical pendular nystagmus with a mean amplitude of $0.6^{\circ}$. Monkey 2 had an exotropia measuring $10-15^{\circ}$, which increased slightly in upgaze. In both animals the acuity of each eye was measured through performance of a two-alternative discrimination task (Kiorpes, 1992; Kiorpes et al., 1993). A Dell P1130 monitor incorporating a Sony Trinitron cathode ray tube was positioned at $2 \mathrm{~m}$. Each trial commenced with fixation of a central spot. This triggered display of a flanking pair of equiluminant patches measuring $3^{\circ} \times 7^{\circ}$ and simultaneous extinction of the fixation spot. The animal signaled which patch contained a grating by making a saccade to a spot located near the lateral edge of each patch. An interleaved staircase procedure was used to determine the contrast threshold at seven spatial frequencies $(16,8,4$, $\left.2,1,0.5,0.25 \mathrm{cycles}^{\circ}\right)$. The criterion for decreasing the contrast at each spatial frequency was two consecutive correct responses; three consecutive incorrect responses increased the contrast. Threshold was defined by seven reversals in contrast. After the animals mastered the task, data were acquired over several sessions.

\section{Eye tracking}

Monkeys were seated comfortably in a primate chair with the head fixed to record eye movements with video-oculography. Dual independent infrared trackers, sampling at $60 \mathrm{~Hz}$, recorded horizontal and vertical components of each eye's position (SensoMotoric Instruments). The trackers and infrared light sources were positioned eccentrically to allow accurate tracking of each eye from $30^{\circ}$ nasally to $60^{\circ}$ temporally. Gain and offset were calibrated for each eye while the fellow eye was occluded with a filter, which could be moved into position by a pneumatic piston under computer control. The filter transmitted infrared wavelengths so that the eye's position could still be recorded when it was covered. Eye and stimulus positions were sampled at $120 \mathrm{~Hz}$ by a Power1401 data 
acquisition and control system (Cambridge Electronics Design). The monkey was rewarded for sustained fixation with a puree of blended biscuits, fruit, and juice.

\section{Neuronal recording}

Platinum/tungsten tetrodes sheathed in quartz glass (0.5-1.0 $\mathrm{M} \Omega$ ) controlled with a Mini Matrix microdrive system (Thomas Recording) were used to record from the occipital operculum and buried calcarine cortex. The tetrode fiber $(100 \mu \mathrm{m}$ diameter $)$ was passed through the dura without inserting a guide tube to avoid cortical damage (Adams et al., 2011). The tetrode channels were recorded digitally at $25 \mathrm{kHz}$ and saved to disk for off-line spike sorting to identify single units (Spike 2 software, Cambridge Electronics Design).

Each monkey was trained to fixate a $0.25^{\circ}$ spot at $57 \mathrm{~cm}$ rear-projected onto a large tangent screen. The fixation spot could appear at either of two positions, straddling the midline, separated by the magnitude of the strabismic deviation. The monkeys used their left eye to fixate when the spot appeared on the left and the right eye when on the right (Economides et al., 2007; Das, 2009). Consequently, only a small corrective eye movement was needed to alternate fixation when the spot shifted from one side to the other. This eye movement was important, because it confirmed that the monkey indeed had switched fixation.

The tetrode was advanced until a well-isolated, responsive cell was encountered. The size and location of the receptive field were mapped manually. Responses were then tested to stimuli consisting of achromatic sine-wave gratings, nominally $100 \%$ contrast, moving in 8 different directions at $4 \%$. Either a single grating, or a pair of identical gratings, was displayed. They appeared within a circular aperture with a diameter of $2-10^{\circ}$, depending on the size of the cell's receptive field. Gratings frequencies were $1 \mathrm{cycle}^{\circ}$ for cells on the operculum $\left(0-8^{\circ}\right.$ eccentricity) and 0.5 cycles $/{ }^{\circ}$ for cells in calcarine cortex $\left(>8^{\circ}\right.$ eccentricity). Each trial consisted of $250 \mathrm{~ms}$ of full field gray, followed by $250 \mathrm{~ms}$ of drifting grating, followed by $250 \mathrm{~ms}$ of full field gray. The mean luminance of the grating was equal to that of the gray background. If the monkey maintained fixation during the entire $750 \mathrm{~ms}$ period a pulse of puree reward was supplied. Intertrial interval was variable but lasted at least $250 \mathrm{~ms}$.

\section{Pitfalls of recording in awake, strabismic monkeys}

Single unit recordings in awake, strabismic monkeys pose problems that deserve special consideration. These issues can make it difficult to stimulate accurately the receptive fields of V1 cells, owing to their very small size.

The first problem is that video eye tracking systems are not as accurate or rapid as scleral search coils (Kimmel et al., 2012). Despite these disadvantages, video eye trackers were chosen for this project because implantation of scleral search coils posed a risk of altering the strabismus angle that had been induced in each monkey postnatally. Video trackers have an accuracy no better than $0.5-1.0^{\circ}$ (van der Geest and Frens, 2002; Träisk et al., 2007; Choe et al., 2016; Hooge et al., 2016). We have recorded a positional accuracy of $\pm 0.75^{\circ}$ within $15^{\circ}$ of primary gaze during tracking in strabismic monkeys (Economides et al., 2007). Higher gaze angles produce even more error. Our approach of having fixation targets straddle the midline kept each eye within $15^{\circ}$ of primary gaze, and hence improved tracker fidelity.

The second problem is that the eyes are inherently unstable in strabismus (Pirdankar and Das, 2016). Some subjects, like Monkey 1, have nystagmus. Even in subjects without nystagmus, the fixating eye in strabismus is less stable in position than either eye of a normal subject with bifoveal fixation (Economides et al., 2016). The deviating eye's position is even more unstable, constantly shifting location during binocular viewing (Economides et al., 2007). A plot of the fixating eye's position at the moment of grating(s) appearance forms a cloud spanning several degrees, and the deviating eye's positions are even more dispersed (Fig. $2 A$ ). To mitigate this instability, foveal position recorded $50 \mathrm{~ms}$ before grating display was used to update receptive field location on the tangent screen for each eye. This feedback improved the accuracy of stimulus placement by partially offsetting trial-to-trial variation in eye positions. However, after onset of the grating stimulus, small uncorrected movements continued to occur in both eyes, especially in the deviating eye. These movements shifted the relative positions of the eyes during the $250 \mathrm{~ms}$ grating display by a median absolute value of $0.54^{\circ}$ (Fig. $2 B$ ).

Some cells in strabismic monkeys have been reported to retain sensitivity to retinal disparity (Smith et al., 1997; Kumagami et al., 2000; Mori et al., 2002). In these studies, recordings were made in animals under general anesthesia with the eyes immobilized by neuromuscular blockade. This made it possible to control precisely the phase of the grating presented to each eye. In our experiments the positions of the eyes were too unstable, relative to the width of the test grating, to allow measurement of sensitivity to retinal disparity (Fig. 2C). In fact, the relative movements of the eyes meant that, by chance, all phase relationships were tested.

The third problem is that animals with strabismus may have ocular cyclorotation. The development of cyclorotation is unpredictable. In a previous study two animals underwent bilateral medial rectus muscle tenotomy to induce exotropia (Economides et al., 2018). Although the surgery was identical, one animal developed a relative incyclotorsion of $20^{\circ}$ while the other animal had no significant cyclotorsion. When cyclorotation is present, its magnitude can change with gaze angle. Gaze angle was held nearly constant in our experiments, but the globes could still potentially cyclorotate back and forth as fixation switched between the eyes (Guyton, 2008). This phenomenon could induce a shift in the polar angle of receptive field locations with changes in eye of fixation. Our video eye trackers are not capable of detecting globe cyclorotation, so it was important to determine whether it was present. V1 receptive fields for 6 binocular units were mapped using reverse correlation of a sparse noise stimulus comprised of $1^{\circ}$ elements as each monkey alternated fixation (Fig. 3) (Economides et al., 2018). Relative cyclorotation in each animal measured $<1.5^{\circ}$, allaying this concern.

Eye tracker inaccuracy, imprecise fixation, nystagmus, fluctuating ocular deviation, and imperfect hand mapping of receptive fields each contribute to the risk that grating stimuli might be incorrectly placed, especially in the deviating eye. This risk is heightened by the fact that most units in strabismic animals respond well to only one eye, making it difficult to pinpoint the location of the receptive field in the other eye. Misplacement of the grating displayed to the "silent" eye could confound assessment of interocular suppression. To reduce this hazard, we used 

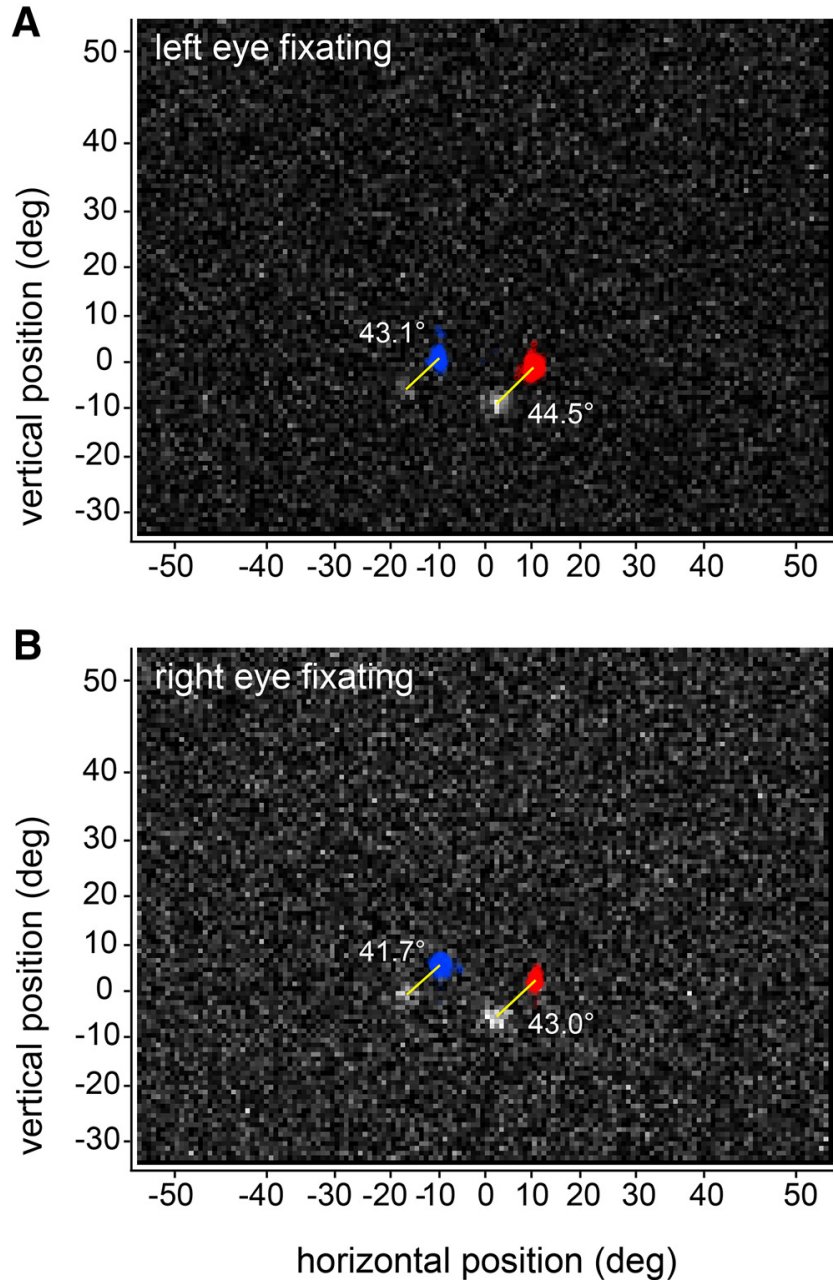

Figure 3. Sparse noise mapping of V1 receptive fields to measure relative globe cyclorotation during epochs with the $(\boldsymbol{A})$ left eye fixating and the $(\boldsymbol{B})$ right eye fixating in Monkey 1. Images represent the spike-triggered average stimulus generated from a sparse noise pattern comprised of 35 randomly distributed white squares $\left(1^{\circ}\right.$ side) per frame $(15 \mathrm{~Hz})$ displayed against a dark background. Yellow lines represent the vector between mean eye positions (blue cluster = left eye, red cluster $=$ right eye) and receptive field centers which were located at $10.1^{\circ}$ eccentricity. Numbers denote the polar angle measured for each vector (horizontal meridian $=0^{\circ}$ ). The relative globe cyclorotation, and the change in cyclorotation that occurred with a fixation switch were $<1.5^{\circ}$.

gratings that were at least twice the diameter of the hand-mapped, classical receptive field. The diameter of most gratings was $4-8^{\circ}$, and none measured $<2^{\circ}$. The drawback was that inclusion of the non-classical surround tends to reduce firing rates (Gilbert and Wiesel, 1990; Zipser et al., 1996; Levitt and Lund, 2002). For each cell, we selected a stimulus that was large enough to be sure that it landed on the receptive field, but small enough not to reduce excessively the cell's firing rate (Xing et al., 2005).

\section{Data quantification and statistical analysis}

For each neuron a peristimulus time histogram with $5 \mathrm{~ms}$ bins was computed for each presentation condition. The baseline firing rate was derived from the $100 \mathrm{~ms}$ period before stimulus onset. The neuronal response (R) was defined as the mean firing rate following stimulus presentation minus the baseline firing rate. For neurons with a substantial transient and sustained response, the mean firing rate was calculated for 50-400 ms after stimulus onset. For neurons with a weak sustained response (mean firing rate from 100 to $400 \mathrm{~ms}$ after stimulus onset $\leq 1.5$ times baseline firing rate), only the transient component from 50 to $100 \mathrm{~ms}$ after stimulus onset was used. This avoided the problem, encountered for some highly transient units with a relatively high background
A

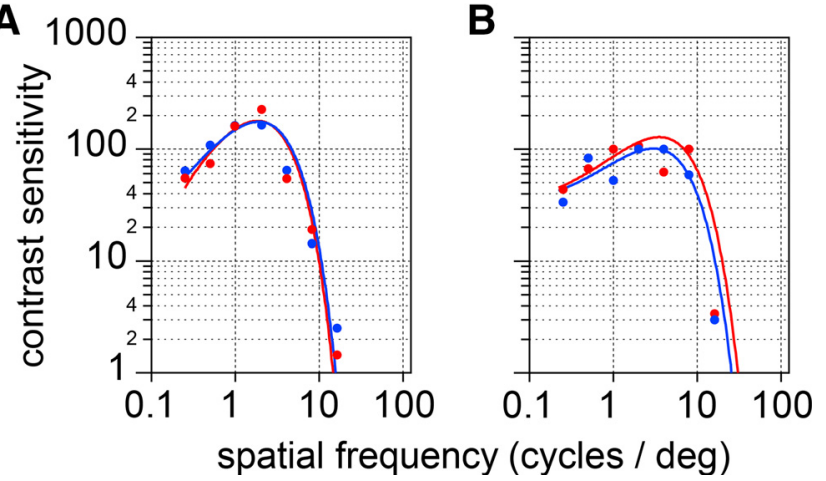

Figure 4. Contrast sensitivity versus spatial frequency plotted for the left eye (blue) and right eye (red) in (A) Monkey 1 and (B) Monkey 2 showing similar acuity in the eyes.

firing rate, of spurious index values caused by averaging of the transient response over an excessively long-time interval.

Five indices were computed for each unit to compare responses under different stimulus conditions. In Results, each index is diagrammed and explained, along with details regarding statistical design and analysis, but formal definitions are provided here. Each index could span a value from 0 to 1

Ocular dominance index (ODI)

It compares the ability to drive a neuron by stimulation of the contralateral (left) versus the ipsilateral (right) eye. For these trials the fellow eye was occluded.

$$
\mathrm{ODI}=\frac{R_{\text {righteye }}}{R_{\text {righteye }}+R_{\text {lefteye }}}
$$

The firing rate during stimulation of the non-dominant eye sometimes dipped slightly below the background firing rate. This could result in an ODI $<0$ or $>1$. In these cases, the ODI was rounded to 0 (total left eye dominance) or to 1 (total right eye dominance). The ODI was divided evenly to form a traditional seven-bin ocular dominance histogram (bin $1=0.000-0.143$, bin $2=0.143-0.286$, etc.).

\section{Receptive field interaction index (RFII)}

It compares the response to stimulation of the receptive field in the dominant eye $\left(R_{\text {best }}\right)$ to the response to simultaneous stimulation of the receptive fields in both eyes $\left(R_{\text {binocular }}\right)$. Under both stimulus conditions, both eyes were open while the dominant eye fixated. In this context, "dominant" refers to the eye that drove the cell most effectively, not to the eye the animal preferred to acquire targets with during free viewing.

$$
R F I I=\frac{R_{\text {binocular }}}{R_{\text {best }}+R_{\text {binocular }}}
$$

The RFII revealed interocular receptive field interactions, ranging from maximally suppressive $(\mathrm{RFII}=0)$, to absent $(\mathrm{RFII}=0.5)$ to maximally faciliatory $(\mathrm{RFII}=1)$.

Ocular fixation index, both fields (OFI $\left.I_{\text {both fields }}\right)$

It compares the response to simultaneous stimulation of the receptive fields in both eyes during trials of right eye fixation versus left eye fixation.

$$
O F I_{\text {bothfields }}=\frac{R_{\text {binocular (right eye fixation) }}}{R_{\text {binocular (right eye fixation) }}+R_{\text {binocular (left eye fixation) }}}
$$

The index is 0 for neurons that responded only during left eye fixation and it is 1 for those that responded only during right eye fixation. It equals 0.5 if eye of fixation had no impact. 
A

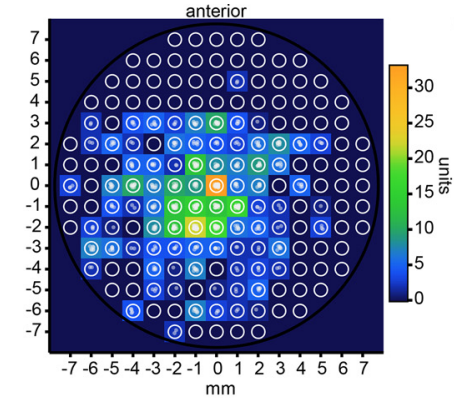

C

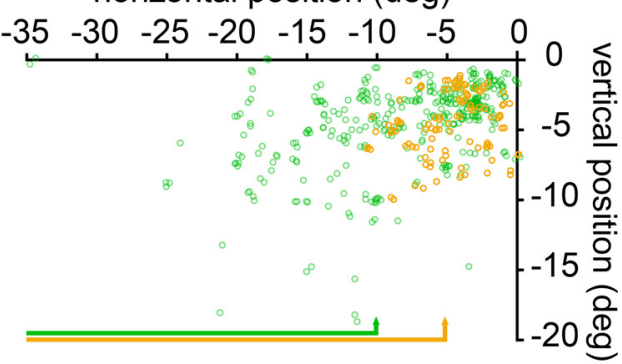

B

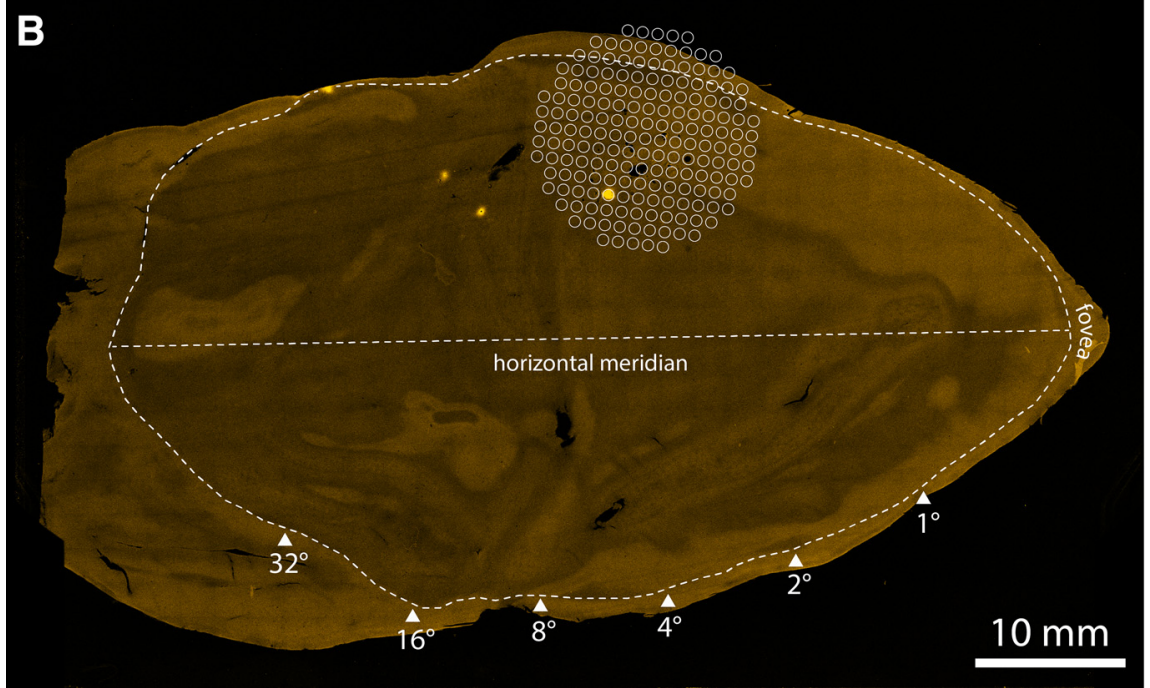

Figure 5. Recording sites and receptive field locations. $A$, Diagram of holes in a Delrin grid through which tetrode penetrations were made in both monkeys. The anterior four rows were avoided to ensure that opercular recordings were made in V1. Holes near the grid periphery were seldom used because of bony ingrowth. $\boldsymbol{B}$, CO flatmount section from Monkey 1 imaged with a Zeiss LSM900 microscope to show fluorescent FM 1-43FX label from the last electrode penetration. The electrode passed through the right V1 on the operculum (hole coordinate: $-2,-4$ ) and at three additional sites in the folded calcarine fissure, the last along the V1/N2 border. Each penetration hole in the grid was associated with a different constellation of peripheral recording sites. Dashed line $=$ V1/N2 border. $C$, Receptive field locations in the left lower visual quadrant for the 500 cells recorded in Monkey 1 (green) and Monkey 2 (orange), corrected for display on a tangent screen. The receptive fields of 3 units are not plotted because they were located in the far periphery. Cells beyond an eccentricity of $10^{\circ}$ (green arrow) in Monkey 1 and $5^{\circ}$ (orange arrow) in Monkey 2 were located in cortex containing $\mathrm{CO}$ columns, and hence, might be expected to show suppression if dominated by the right eye.

\section{Peripheral retina interaction index (PRII)}

It compares the best monocular response with the other eye occluded $\left(R_{\text {best monocular }}\right)$ to the response to the same stimulus with the other eye open $\left(R_{\text {best }}\right)$.

$$
\text { PRII }=\frac{R_{\text {best }}}{R_{\text {best }}+R_{\text {best monocular }}} .
$$

The purpose of this index was to examine the impact of a stimulus falling on the peripheral temporal retina of the deviating eye, by comparing trials of the response in the dominant eye with the deviating eye either open or occluded. For all trials, the dominant eye foveated the fixation spot. The PRII is 0 for maximal suppression, 0.5 for no effect, and 1 for maximal facilitation.

Ocular fixation index, single field ( $\left.O F I_{\text {single field }}\right)$

It compares the response with both eyes open to stimulation of the dominant eye's receptive field during trials of dominant eye fixation $\left(R_{\text {best }}\right)$ versus fellow eye fixation $\left(R_{\text {same field, fellow eye fixation }}\right)$.

$$
O F I_{\text {single field }}=\frac{R_{\text {best }}}{R_{\text {best }}+R_{\text {same field, felloweye fixation }}} .
$$

This index equals 0 if fixation by the dominant eye suppressed the response in the dominant eye. It equals 1 if fixation by the fellow eye suppressed the response in the dominant eye. It is 0.5 if eye of fixation made no difference.

\section{Histologic correlation}

V1 was examined in each monkey to reveal the pattern of $\mathrm{CO}$ activity. For the last recording session, the tetrode was coated with a fluorescent tracer, FM 1-43FX (ThermoFisher Life Technologies; Simmons et al., 2020). The monkeys received a lethal injection of pentobarbital and were then perfused with $1 \mathrm{~L}$ normal saline followed by $1 \mathrm{~L}$ of $0.5 \%$ paraformaldehyde in $0.1 \mathrm{M}$ phosphate buffer. V1 was unfolded, flat-mounted, and sectioned tangentially at $60 \mu \mathrm{m}$ with a freezing microtome (Horton and Hocking, 1996). After drying on a slide, each section was processed for CO histochemistry (Wong-Riley, 1989) and FM 1-43FX was visualized using appropriate filters. Optical density of $\mathrm{CO}$ reaction product was quantified as described previously (Horton and Hocking, 1998).

\section{Results}

\section{Alternating exotropia without} amblyopia

Monkeys with exotropia induced by eye muscle surgery usually alternate fixation freely and hence develop normal acuity in each eye. We have raised eight monkeys with surgical exotropia over 15 years. Only one has become amblyopic (Adams et al., 2015). This single exception, nonetheless, compelled us to test the acuity of the two monkeys used in this study before commencing recordings.

Figure 4 shows plots of contrast sensitivity as a function of spatial frequency for each eye. Neither animal showed any difference between the eyes in contrast sensitivity. The plots were similar to those reported in normal animals (Harwerth et al., 1983; Kiorpes et al., 1987, 1998; Kiper and Kiorpes, 1994). The finding of normal acuity in each eye was welcome, because it allowed us to study the mechanism of suppression without the potentially confounding issue of amblyopia.

\section{Recordings in V1}

Electrode penetrations were oriented using a grid inserted inside the chamber during recordings (Fig. $5 A$ ). In the beginning, recordings were confined to the operculum $\left(2-8^{\circ}\right)$, avoiding the anterior four grid rows to make sure that tetrodes did not enter V2. In later recordings we targeted calcarine cortex $\left(8-40^{\circ}\right)$. Penetrations were made through posterior rows to avoid traversing extrastriate cortex at the bottom of the lunate sulcus. Figure $5 B$ shows the penetration marked by coating the electrode with a fluorescent dye for the last recording session in Monkey 1. It passed through opercular cortex and then through three sites in calcarine cortex. Because each grid hole was associated with a different trajectory through $\mathrm{V} 1$, receptive fields were widely scattered in the contralateral visual field (Fig. 5C). It was important that many eccentricities were sampled, because suppression involves only a portion of the visual field in each eye. Although the upper visual quadrant was not explored, suppression 


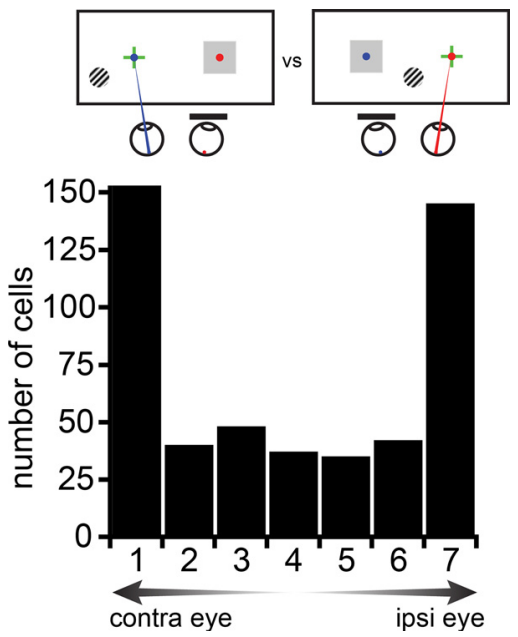

Figure 6. ODI shows loss of binocularity in strabismus. Histogram of the ODI showing the relative strength of the response to stimulation of the receptive field in the left (contra) eye versus the right (ipsi) eye for all 500 cells. Compared with normal monkeys (Hubel and Wiesel, 1977) a higher proportion of cells were dominated by one eye, but most cells were still binocular. In cartoons, green cross indicates fixation spot's position, blue dot is left eye's position, red dot is right eye's position, gray square denotes occlusion, grating represents stimulus on cell's receptive field.

scotomas in exotropia have vertically oriented borders, involving upper and lower visual quadrants symmetrically (Cooper and Feldman, 1979; Economides et al., 2012).

Ocular dominance profile of cortical cells

A total of 389 cells were recorded in Monkey 1 and 111 cells in Monkey 2. Although more cells were recorded in Monkey 1, their data are merged because the two animals yielded very similar findings.

An ocular dominance histogram revealed loss of cells that responded to stimulation of both eyes (Fig. 6) (Hubel and Wiesel, 1965; Wiesel, 1982). The impact of strabismus was striking, but most cells could still be driven via both eyes. Of the 298 cells in categories 1 and 7, 131 responded weakly to the nondominant eye. Categories 2-6 comprised 202 cells. Therefore, $333 / 500$ (67\%) cells were binocular. The presence of preserved binocular interactions in the majority of cells was auspicious, because it increased the likelihood of detecting interocular suppression or facilitation in these strabismic monkeys.

Typical V1 responses to stimulus conditions in strabismus For each isolated single neuron the responses were recorded for eight different trial types while the monkey fixated a small spot. The neuron in Figure 7 was typical of the great majority of cells. With either eye occluded, monocular trials (Fig. 7A,E) showed that it was strongly dominated by one eye. In this case it was the right eye, corresponding to an ODI of 0.88 (category 7).

With both eyes open and the right eye fixating, stimulation of the right eye's receptive field (Fig. $7 B$ ) versus both eyes' receptive fields (Fig. 7C) made little difference. The RFII, a measure of this binocular interaction, was 0.55 . During trials when gratings were displayed to both eyes' receptive fields, responses were similar for right eye fixation (Fig. $7 C$ ) versus left eye fixation (Fig. $7 G$ ), as reflected by an $\mathrm{OFI}_{\text {both fields }}$ equal to 0.46 .

As explained in Figure 1, the most interesting trials relevant to the potential mechanism of diplopia suppression were those comparing stimulation of the dominant right eye under conditions where the fellow eye was either occluded (Fig. 7A) or open
(Fig. $7 B$ ). With both eyes open, the grating landed on the right eye's receptive field and the left eye's temporal retina (at the diplopia point). This cell had a PRII of 0.51 , indicating no impact from uncovering the left eye. Concomitant stimulation of the left eye did not reduce the response driven by the right eye, as one might expect if such inhibition were the cortical mechanism for preventing diplopia.

It also made no difference whether the right eye was fixating (Fig. $7 B$ ) or the left eye was fixating (Fig. $7 F$ ) while the dominant right eye's receptive field was being stimulated. The $\mathrm{OFI}_{\text {single field }}$ was 0.47 , signifying a nearly equal response during right eye and left eye fixation trials.

\section{Stimulation of one eye's versus both eyes' receptive fields (RFII)}

While the dominant eye fixated, the response was compared with stimulation of its receptive field versus stimulation of both eye's receptive fields for all 500 cells (Fig. 8). In normal animals, binocular stimulation commonly enhances the firing rate of $\mathrm{V} 1$ neurons. The mean RFII was $0.50 \pm 0.13$, indicating no net facilitation or suppression from binocular stimulation in these strabismic monkeys.

\section{Stimulation of one eye's receptive field, monocular versus binocular viewing (PRII)}

The PRII compared stimulation of the dominant eye's receptive field, with the fellow eye occluded versus open (Fig. 9). The latter condition recapitulates the conditions that give rise to diplopia, namely, a given stimulus landing on non-corresponding points in the two retinas. We anticipated that for many cells, opening the fellow eye might suppress the monocular response. In fact, the mean PRII was $0.51 \pm 0.12$, which was not statistically different ( $p=0.19$, two-tailed $t$ test) from an ideal population of 500 neurons with equal variance having no facilitation or suppression $(P R I I=0.50)$. Unexpectedly, there was no overall tendency for stimulation of the diplopia point in the deviating eye to cause suppression of V1 neurons.

\section{No effect of ocular fixation}

It is commonly believed that in strabismus, signals emanating from the deviating eye are more likely to be suppressed. If so, one might expect to find that suppressive effects correlate with eye of fixation. Two indices addressed this question. The $\mathrm{OFI}_{\text {both fields }}$ compared neurons' responses to stimulation of both eyes' receptive fields under conditions of fixation by the right eye versus the left eye. For the 500-cell population, the mean $\mathrm{OFI}_{\text {both fields }}$ was $0.50 \pm 0.14$, indicating that it made no overall difference which eye fixated during testing (Fig. 10). It therefore seems unlikely that eye of fixation is encoded in V1 because few cells showed robust modulation of their response when the eyes swapped fixation.

The $\mathrm{OFI}_{\text {single field }}$ compared the response to stimulation of just the dominant eye's receptive field under binocular viewing conditions during fixation by the dominant eye versus the fellow eye. The mean $\mathrm{OFI}_{\text {single field }}$ was $0.52 \pm 0.15$, indicating no overall reduction in the response generated via the dominant eye when the non-dominant eye is engaged in fixation (Fig. 11).

The values of these two indices indicate that for the great majority of V1 cells, eye of fixation is irrelevant to neuronal responses in strabismic subjects. This finding is consistent with the observation that suppression scotomas do not shift location in the visual field with switches in ocular fixation (Economides et al., 2014; see Fig. 9) 


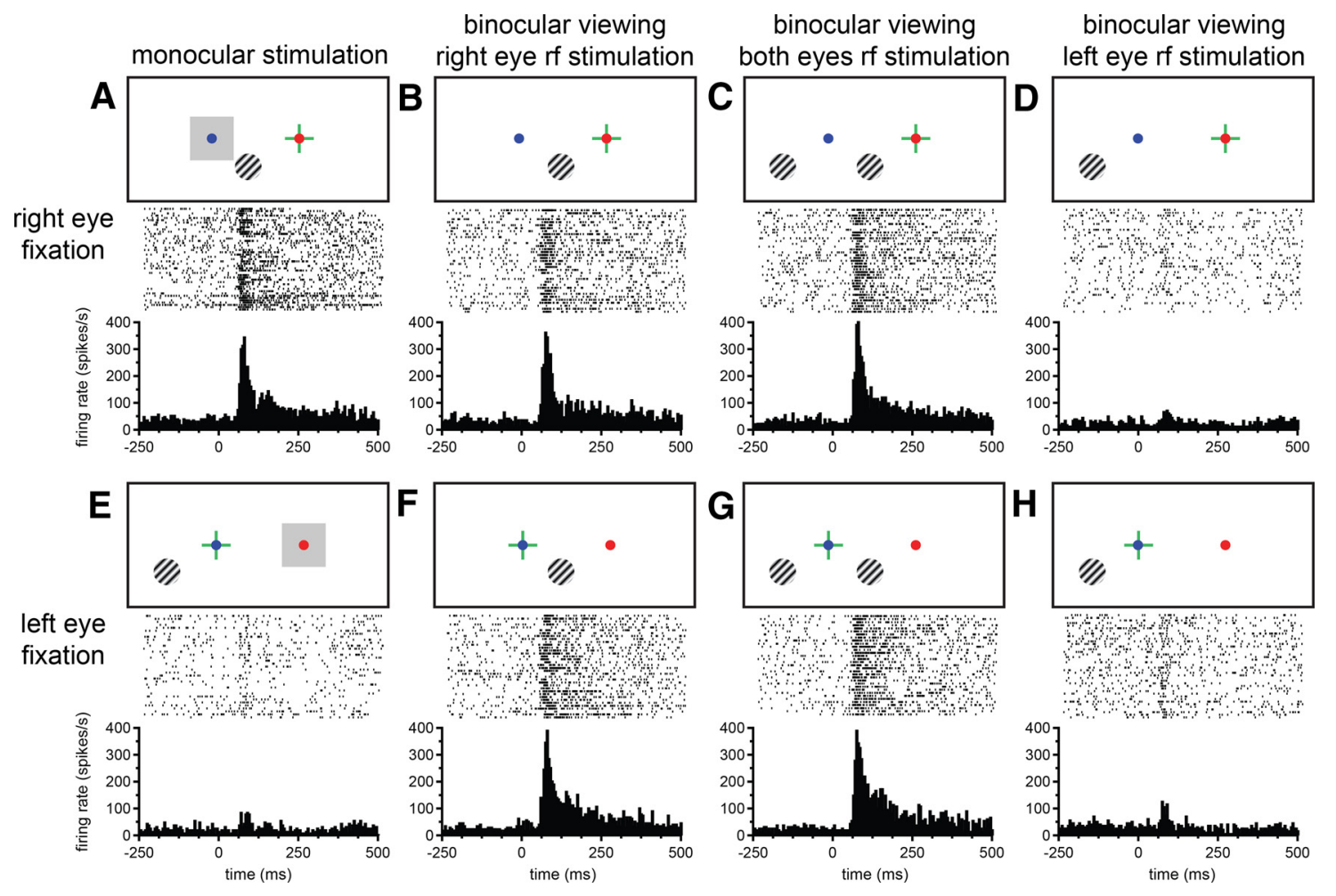

Figure 7. Raster plots and peristimulus time histograms of a representative neuron's responses recorded in Monkey 1 to $\sim 35$ presentations of the 8 stimulus conditions. The receptive field was centered at $12.5^{\circ}$ left and $9.5^{\circ}$ below each fovea. The grating was 1 cycle $/{ }^{\circ}$ and $5^{\circ}$ in diameter. Top row $(\boldsymbol{A}-\boldsymbol{D})$ shows right eye fixation conditions, and bottom row $(\boldsymbol{E}-\boldsymbol{H})$ shows left eye fixation conditions. Like most units, this cell showed no facilitation, suppression, or change in firing with fixation switch. If $=$ receptive field.

Reduced CO activity in ocular dominance columns driven by ipsilateral peripheral retina

Figure $12 A$ shows a flatmount section from Monkey 2 passing mostly through layer 4 . In unfolded calcarine cortex, representing peripheral visual field, alternating light and dark columns of $\mathrm{CO}$ activity were present. Optical density was sampled at 85 sites in light columns and 85 sites in dark columns. The mean optical density was $0.31 \pm 0.08$ for light columns and $0.34 \pm 0.09$ for dark columns. In layers $2 / 3$ rows of CO patches appeared light or dark, in register with the columns in layer 4. Previously, it was established by correlation with $\left[{ }^{3} \mathrm{H}\right]$ proline autoradiography that the pale columns are supplied transneuronally by the temporal retina of the ipsilateral eye (Adams et al., 2013). Consistent with that finding, the monocular crescent representation appeared dark and the blind spot representation was light (Fig. 12A). In these locations CO columns were absent.

The reduction of metabolic activity in ocular dominance columns serving the peripheral temporal retina has been shown to correspond to the location of nasal suppression scotomas in each eye in subjects with alternating exotropia (Economides et al., 2012). Accordingly, one would predict that ipsi-eye dominated neurons with receptive fields located in peripheral nasal visual field would show the strongest interocular suppression (Fig. 1). Such suppression might explain the pale CO columns in the peripheral cortex.

Pale ocular dominance columns were present in striate cortex representing eccentricities from $10^{\circ}$ to the monocular crescent in Monkey 1 and from $5^{\circ}$ to the monocular crescent in Monkey 2. A combined total of 94 right-eye dominant neurons (ODI $>0.5$ ) was recorded in these regions (Fig. 12B). Presumably, most of these neurons were situated in pale ocular dominance columns. Their mean PRII was $0.50 \pm 0.09$ [95\% confidence interval (CI)
0.48-0.51; Fig. 12C]. There were 98 left-eye dominant neurons $(\mathrm{ODI}<0.5)$ recorded in peripheral cortex containing CO columns. Their PRII was $0.50 \pm 0.13$ (95\% CI 0.48-0.53). The lack of any difference in mean PRII indicated that neurons located in pale CO columns were no more likely to be suppressed during binocular viewing than neurons recorded in dark columns.

It is possible that comparing the PRII for all neurons recorded within cortical zones containing CO columns diluted an effect present only in those neurons most strongly dominated by one eye. We therefore compared neurons just in category 1 versus 7 (Fig. 12B). The PRII for the 59 category 1 neurons was $0.48 \pm 0.10(95 \%$ CI $0.45-0.51)$ and the PRII for the 56 category 7 neurons was $0.50 \pm 0.09$ (95\% CI 0.47-0.52). Even for those neurons driven almost exclusively by the right eye, there was no net suppressive effect compared with neurons favoring the left eye.

The pale CO columns in peripheral cortex might be explained by an absolute difference in neuronal activity driven by each eye. For the 94 neurons dominated by the right eye the mean background firing rate was $16.8 \pm 16.7$ spikes/s (95\% CI 15.4-18.2). For the 98 neurons dominated by the left eye the mean background firing rate was $15.4 \pm 16.5$ spikes/s (95\% CI 14.0-16.7). For the right eye neurons, $R_{\text {best }}$ (response to stimulation of the eye's receptive field under binocular viewing conditions) was $52.0 \pm 45.2 \mathrm{spikes} / \mathrm{s}$ (95\% CI 42.7-61.3). For the left eye neurons, $R_{\text {best }}$ was $45.5 \pm 37.2$ spikes/s (95\% CI 38.0-52.9). There was no significant difference in either background or stimulus-driven spike rates between neurons preferring the right eye or the left eye.

The mean $\mathrm{OFI}_{\text {single field }}$ for the 94 peripheral right-eye dominant neurons was $0.51 \pm 0.12$ (95\% CI 0.48-0.53; Fig. 12D). This value indicated a lack of net suppression in this subpopulation, regardless which eye fixated during binocular viewing. 

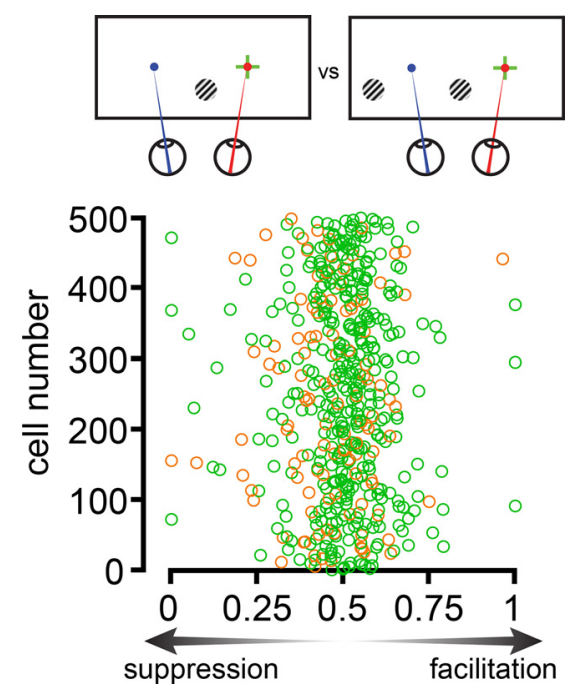

Figure 8. RFIl. This index compares stimulation of the receptive field in the dominant eye to stimulation of the receptive fields in both eyes. As shown in the cartoon, both eyes viewed while the dominant eye fixated. Each circle represents data from a single cell (green = Monkey 1 ; orange $=$ Monkey 2 ). There is no net suppression or facilitation.
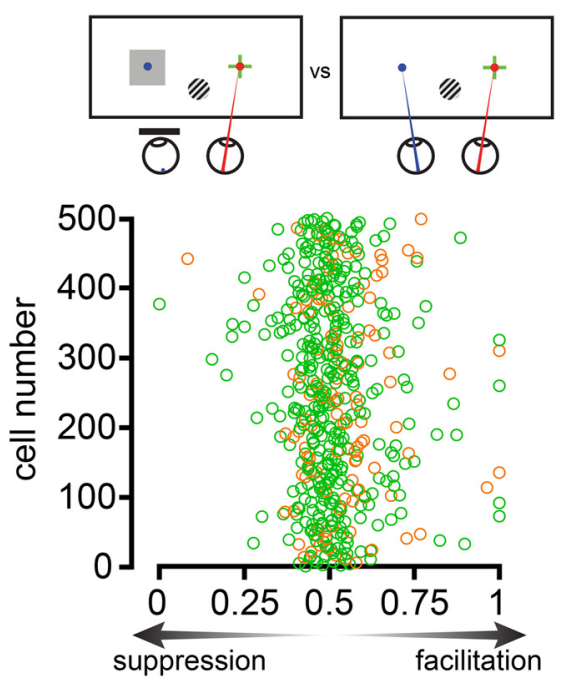

Figure 9. PRII. This index compares stimulation of the dominant eye's receptive field with the fellow eye occluded versus open. The mean PRII was $0.51 \pm 0.12$, reflecting no suppression or facilitation for the neuronal population.

\section{Discussion}

Every person has a phoria, or tendency for the eyes to drift out of alignment. It is overcome by an innate drive to overlap corresponding retinal images into a single percept. When the eyes become misaligned, the sensation of diplopia induces a change in the tension exerted by the extraocular eye muscles. The eyes are brought back into register, restoring fusion and stereopsis. In strabismus, this corrective sensory feedback loop fails because one image is suppressed. Failure to appreciate diplopia is one reason that eye muscle surgery is often unsuccessful at restoring ocular alignment in children with strabismus (Wan et al., 2018; Chougule and Kekunnaya, 2019). The goal of this study was to uncover the cortical mechanism of visual suppression, with the aim of improving treatment for strabismus. It seemed sensible to begin the search in V1, because it is the first place in the visual sensory pathway where ocular inputs are brought together. It is
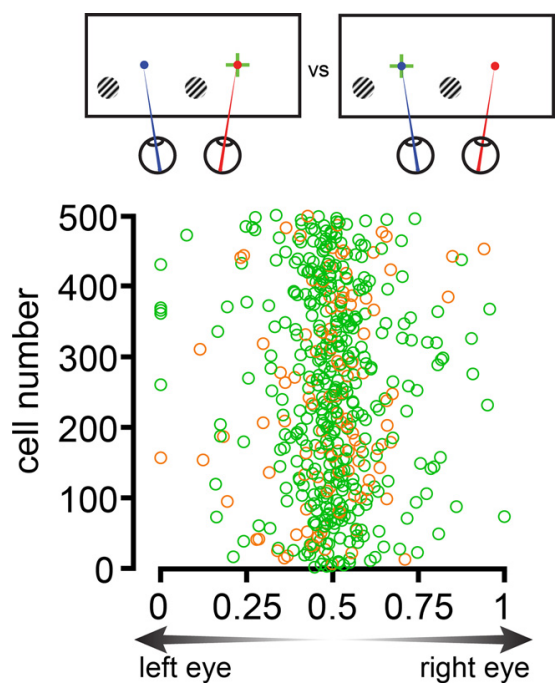

Figure 10. $\quad \mathrm{OFI}_{\text {both fields. }}$. This index compares the neuronal response to stimulation of both eyes' receptive fields during trials of right eye fixation versus left eye fixation. The mean $0 \mathrm{FI}_{\text {both fields }}$ was $0.50 \pm 0.14$, indicating that neuronal responses showed no net modulation with eye of fixation. A bimodal distribution would have suggested a correlation between eye of fixation and neuronal activity.
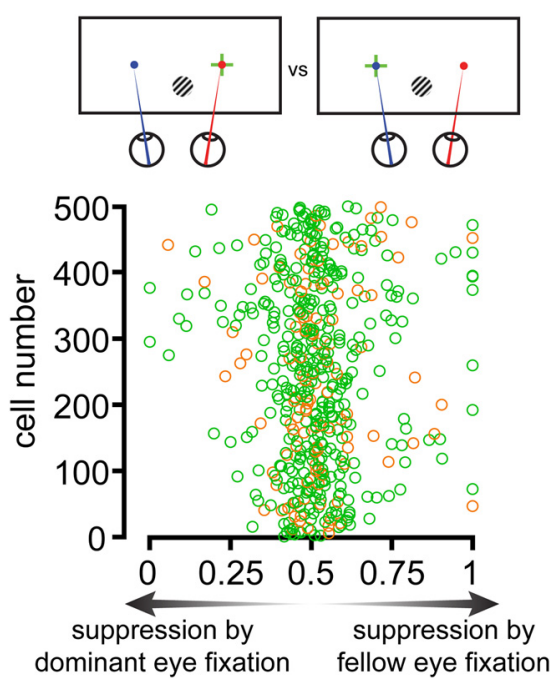

Figure 11. $\quad \mathrm{OF}_{\text {single field. }}$ This index compares the neuronal response to stimulation of the dominant eye's receptive field, with both eyes viewing, during epochs of fixation by the dominant eye versus with fellow eye. The mean $\mathrm{OFI}_{\text {single field }}$ was $0.52 \pm 0.15$. The response in the dominant eye was not suppressed, except in a handful of cells, when the fellow eye fixated.

also the last place where they are partly segregated, potentially allowing signals from one eye to inhibit transmission of those from the other eye.

As expected, strabismus reduced the number of cells that could be driven by monocular stimulation of both the right eye and the left eye (Fig. 6). In their pioneering study in kittens with exotropia, Hubel and Wiesel (1965) reported that the percentage of binocular cells fell from $80 \%$ to $20 \%$. We found a higher percentage of cells (67\%) with retained binocularity. Other investigators have also reported better preservation of binocularity (Crawford and von Noorden, 1980; Freeman and Tsumoto, 1983; Chino et al., 1994; Sengpiel et al., 1994; Smith et al., 1997; Kumagami et al., 2000; Mori et al., 2002; Scholl et al., 2013). Of course, the exact percentage of binocular cells depends on many 
factors, such as the species, the age of strabismus onset, and the threshold for defining a response as binocular.

A more striking effect from strabismus was the lack of any net facilitation or inhibition from stimulation of both eyes' receptive fields (Fig. 8). In our recordings, the response to a grating presented to the receptive field in one versus both eyes yielded a mean RFII of exactly 0.50 . In normal animals, stimuli presented simultaneously to both eyes' receptive fields evoke a different response than do stimuli presented monocularly. Depending on the cell's disparity tuning, the response may be augmented or reduced (Poggio and Fischer, 1977; Poggio et al., 1988; DeAngelis et al., 1991; Prince et al., 2002; Dougherty et al., 2019). In general, cells have a maximal binocular response that is greater than the strongest monocular response. For example, Smith et al. (1997) reported that the response to stimuli presented at the optimal retinal disparity had a peak binocular amplitude that was 38\% greater for simple cells and 55\% greater for complex cells than the monocular response in the dominant eye. In prism-reared monkeys, simple cells showed only $18 \%$ binocular facilitation and complex cells actually showed $5 \%$ binocular inhibition. The facilitation they observed in simple cells may have been because of residual sensitivity to retinal disparity, a property we could not assess in awake, strabismic monkeys. Otherwise, our data are in close agreement. They are also in accord with a study in strabismic cats that found no binocular modulation of the best monocular response when stimuli were displayed simultaneously to cells' receptive fields (Sengpiel and Blakemore, 1994; Sengpiel et al., 1994).

In strabismus, identical stimuli do not fall on corresponding points in the two retinas. Objects in the visual scene that land on corresponding points are always different, which creates the potential for visual confusion. Therefore, comparison of the response to stimulation of the receptive field in one eye versus both eyes, using stimuli that are identical, fails to model accurately the conditions in strabismus. In our recordings, the absence of binocular facilitation under these conditions was anticipated, given the animals' history of strabismus. The lack of binocular inhibition was also no surprise. Visual confusion is resolved in exotropia not by inhibition, but through a phenomenon termed "anomalous retinal correspondence" (Cooper and Feldman, 1979; Herzau, 1996; Serrano-Pedraza et al., 2011; Economides et al., 2012). In subjects with anomalous retinal correspondence, the spatial registration of one retina is shifted laterally relative to the other. In exotropia, this remapping eliminates the visual confusion that would otherwise occur when dissimilar elements of the visual scene impinge on corresponding retinal loci. It also results in an expansion of the horizontal range of the binocular visual field, enlarging it compared with normal individuals. The physiological basis of anomalous retinal correspondence is still unknown but it presumably involves an altered body-centered frame of reference, rather than suppression of signals from the deviated eye (Grant and Berman, 1991; Sun and Goldberg, 2016).

Diplopia arises because identical images fall on non-corresponding retinal loci. To test this scenario, one must stimulate a cell's receptive field in the dominant eye and the diplopia point in the other eye (Fig. 1). This approach has not been employed in previous strabismus studies. Our recordings yielded a mean PRII of 0.51 (Fig. 9), indicating that for the overall neuronal population, responses driven by the dominant eye were not inhibited by concomitant stimulation of the diplopia point in the deviated eye. For many neurons, the lack of inhibition was expected. For example, if a neuron responds best to the left eye, and its receptive field is located in a portion of the visual field perceived by the left eye during binocular viewing, one would predict no reduction in firing from stimulation of the diplopia point in the right eye. On the other hand, a neuron dominated by the right eye with its receptive field at the diplopia point should be expected to show inhibition on uncovering of the left eye. 
This example highlights a crucial point: inhibition is expected only for certain neurons, namely, those with receptive fields located within a suppression scotoma. In exotropia, a suppression scotoma is present in the peripheral nasal visual field of each eye (Economides et al., 2012; Agaoglu et al., 2014). There is corresponding loss of CO activity in the ocular dominance columns serving the peripheral temporal retina (Adams et al., 2013; see their Fig. 1), suggesting that signals from the ipsilateral eye are chronically inhibited. We calculated the PRII for only those neurons dominated by the ipsilateral right eye, with receptive fields at eccentricities corresponding to cortex where $\mathrm{CO}$ histochemistry revealed pale ocular dominance columns (Fig. 12). Even for this subset of neurons, selected because their receptive fields were located in a presumptive suppression scotoma, there was no net inhibition from stimulation of the other eye (mean PRII $=0.50$ ).

The PRII is a relative measure, comparing discharge rates under conditions of monocular versus binocular viewing. An absolute reduction under both conditions in neuronal activity driven by the right eye might account for the pale CO columns in peripheral cortex. This explanation was ruled out, however, by the finding that peripheral neurons dominated by the right eye had mean baseline firing rates and responses to visual stimulation equal to those of the left eye. Moreover, neurons favoring the right eye $(n=94)$ versus the left eye $(n=98)$ were encountered with equal probability.

The appearance of the dark and pale $\mathrm{CO}$ columns present in these two strabismic monkeys was similar to that observed previously in exotropia (Horton et al., 1999; Adams et al., 2013). The contrast in CO staining was subtle, amounting to a difference of 0.03 in optical density, equivalent to a $3 \%$ difference in light transmittance. The difference in neuronal spike rates corresponding to this difference in metabolic activity is unknown (DeYoe et al., 1995). It might be quite small, perhaps undetectable in our limited sample of 192 cells in peripheral cortex. In rebuttal, we note that eyelid suture also produces $\mathrm{CO}$ columns that are faint, with a difference of only 3\% in transmittance between dark and pale columns (Horton and Hocking, 1998). Nonetheless, eyelid closure has a dramatic effect on neuronal firing, showing that modest differences in relative CO levels, at least under some circumstances, can reflect substantial differences in neuronal firing rates.

We knew before starting these recordings that $\mathrm{CO}$ activity is reduced in columns serving the peripheral temporal retina (Adams et al., 2013). Consequently, we fully expected to find inhibition of neurons dominated by the ipsilateral eye when recording from cortex representing the peripheral nasal visual field. Such a discovery would have provided a neurophysiological mechanism for the suppression of diplopia and accounted for the loss of $\mathrm{CO}$ activity in ipsi-eye columns. Our negative results constitute a perplexing setback.

Although ray diagrams focus on a single point (Fig. 1A), signals from many diplopia points comprising vast regions of temporal retina are suppressed to avoid diplopia in exotropia. The eye engaged in perception of a given segment of the visual scene is believed to mediate suppression of the duplicate image in the other eye. It seems unlikely this process occurs entirely within V1. In a subject with a $25^{\circ}$ exotropia, for example, it would require neurons driven by the dominant eye in cortex representing the central visual field to inhibit cells driven by the deviated eye at the diplopia point $25^{\circ}$ away - a distance of many centimeters (Tychsen, 2005). An even greater challenge is posed by the portion of the visual scene situated between the fixation point of the right eye and the left eye, because the diplopia point is represented in the opposite brain hemisphere (Fig. 1). In V1, few inhibitory projections extend beyond the width of a few ocular dominance columns, and none over a distance of centimeters (Sengpiel et al., 2006; D'Souza and Burkhalter, 2017). Moreover, intracortical projections to cells dominated by the other eye break down in strabismus (Tychsen et al., 2004; Schmidt and Löwel, 2008). While one cannot rule out transmission of inhibitory signals through a series of multiple short projections confined to $\mathrm{V} 1$, it is more probable that higher cortical areas feed back inhibitory signals to the diplopia point in V1 (Romeo et al., 2012; Markov et al., 2014). It shall remain for future investigators to determine why such inhibition depresses CO activity within columns serving the suppressed eye at the diplopia point, but apparently does not reduce neuronal firing rates.

\section{References}

Adams DL, Economides JR, Jocson CM, Horton JC (2007) A biocompatible titanium headpost for stabilizing behaving monkeys. J Neurophysiol 98:993-1001.

Adams DL, Economides JR, Jocson CM, Parker JM, Horton JC (2011) A watertight acrylic-free titanium recording chamber for electrophysiology in behaving monkeys. J Neurophysiol 106:1581-1590.

Adams DL, Economides JR, Sincich LC, Horton JC (2013) Cortical metabolic activity matches the pattern of visual suppression in strabismus. J Neurosci 33:3752-3759.

Adams DL, Economides JR, Horton JC (2015) Contrasting effects of strabismic amblyopia on metabolic activity in superficial and deep layers of striate cortex. J Neurophysiol 113:3337-3344.

Adams DL, Rapone BC, Economides JR, Horton JC (2018) Spontaneous reattachment of the medial rectus after free tenotomy. J Pediatr Ophthalmol Strabismus 55:335-338.

Agaoglu MN, LeSage SK, Joshi AC, Das VE (2014) Spatial patterns of fixation-switch behavior in strabismic monkeys. Invest Ophthalmol Vis Sci 55:1259-1268

Chino YM, Smith EL 3rd, Yoshida K, Cheng H, Hamamoto J (1994) Binocular interactions in striate cortical neurons of cats reared with discordant visual inputs. J Neurosci 14:5050-5067.

Choe KW, Blake R, Lee SH (2016) Pupil size dynamics during fixation impact the accuracy and precision of video-based gaze estimation. Vision Res 118:48-59.

Chougule P, Kekunnaya R (2019) Surgical management of intermittent exotropia: do we have an answer for all? BMJ Open Ophthalmol 4:e000243.

Cooper J, Feldman J (1979) Panoramic viewing, visual acuity of the deviating eye, and anomalous retinal correspondence in the intermittent exotrope of the divergence excess type. Am J Optom Physiol Opt 56:422-429.

Cooper J, Record CD (1986) Suppression and retinal correspondence in intermittent exotropia. Br J Ophthalmol 70:673-676.

Crawford ML, von Noorden GK (1980) Optically induced concomitant strabismus in monkeys. Invest Ophthalmol Vis Sci 19:1105-1109.

D'Souza RD, Burkhalter A (2017) A laminar organization for selective cortico-cortical communication. Front Neuroanat 11:71.

Das VE (2009) Alternating fixation and saccade behavior in nonhuman primates with alternating occlusion-induced exotropia. Invest Ophthalmol Vis Sci 50:3703-3710.

Das VE (2016) Strabismus and the oculomotor system: insights from macaque models. Annu Rev Vis Sci 2:37-59.

DeAngelis GC, Ohzawa I, Freeman RD (1991) Depth is encoded in the visual cortex by a specialized receptive field structure. Nature 352:156-159.

DeYoe EA, Trusk TC, Wong-Riley MT (1995) Activity correlates of cytochrome oxidase-defined compartments in granular and supragranular layers of primary visual cortex of the macaque monkey. Vis Neurosci 12:629-639.

Dougherty K, Cox MA, Westerberg JA, Maier A (2019) Binocular modulation of monocular V1 neurons. Curr Biol 29:381-391.e4. 
Economides JR, Adams DL, Jocson CM, Horton JC (2007) Ocular motor behavior in macaques with surgical exotropia. J Neurophysiol 98:34113422.

Economides JR, Adams DL, Horton JC (2012) Perception via the deviated eye in strabismus. J Neurosci 32:10286-10295.

Economides JR, Adams DL, Horton JC (2014) Eye choice for acquisition of targets in alternating strabismus. J Neurosci 34:14578-14588.

Economides JR, Adams DL, Horton JC (2016) Variability of ocular deviation in strabismus. JAMA Ophthalmol 134:63-69.

Economides JR, Rapone BC, Adams DL, Horton JC (2018) Normal topography and binocularity of the superior colliculus in strabismus. J Neurosci 38:173-182.

Fenstemaker SB, Kiorpes L, Movshon JA (2001) Effects of experimental strabismus on the architecture of macaque monkey striate cortex. J Comp Neurol 438:300-317.

Freeman RD, Tsumoto T (1983) An electrophysiological comparison of convergent and divergent strabismus in the cat: electrical and visual activation of single cortical cells. J Neurophysiol 49:238-253.

Gilbert CD, Wiesel TN (1990) The influence of contextual stimuli on the orientation selectivity of cells in primary visual cortex of the cat. Vision Res 30:1689-1701.

Grant S, Berman NE (1991) Mechanism of anomalous retinal correspondence: maintenance of binocularity with alteration of receptive-field position in the lateral suprasylvian (LS) visual area of strabismic cats. Vis Neurosci 7:259-281.

Guyton DL (2008) Ocular torsion reveals the mechanisms of cyclovertical strabismus: the Weisenfeld lecture. Invest Ophthalmol Vis Sci 49:847857.e6.

Hallum LE, Shooner C, Kumbhani RD, Kelly JG, García-Marín V, Majaj NJ, Movshon JA, Kiorpes L (2017) Altered balance of receptive field excitation and suppression in visual cortex of amblyopic macaque monkeys. J Neurosci 37:8216-8226

Harwerth RS, Smith IIE, Boltz RL, Crawford MLJ, von Noorden GK (1983) Behavioral studies on the effect of abnormal early visual experience in monkeys: spatial modulation sensitivity. Vision Res 23:1501-1510.

Hatt SR, Leske DA, Holmes JM (2009) Awareness of exodeviation in children with intermittent exotropia. Strabismus 17:101-106.

Herzau V (1996) How useful is anomalous correspondence? Eye (London) $10: 266-269$.

Hooge I, Holmqvist K, Nyström M (2016) The pupil is faster than the corneal reflection (CR): are video based pupil-CR eye trackers suitable for studying detailed dynamics of eye movements? Vision Res 128:6-18.

Horton JC, Hocking DR (1996) Intrinsic variability of ocular dominance column periodicity in normal macaque monkeys. J Neurosci 16:7228-7239.

Horton JC, Hocking DR (1998) Monocular core zones and binocular border strips in primate striate cortex revealed by the contrasting effects of enucleation, eyelid suture, and retinal laser lesions on cytochrome oxidase activity. J Neurosci 18:5433-5455.

Horton JC, Hocking DR, Adams DL (1999) Metabolic mapping of suppression scotomas in striate cortex of macaques with experimental strabismus. J Neurosci 19:7111-7129.

Hubel DH, Wiesel TN (1965) Binocular interaction in striate cortex of kittens reared with artificial squint. J Neurophysiol 28:1041-1059.

Hubel DH, Wiesel TN (1977) The Ferrier lecture: functional architecture of macaque monkey visual cortex. Proc R Soc Lond B Biol Sci 198:1-59.

Joosse MV, Simonsz HJ, van Minderhout EM, Mulder PG, de Jong PT (1999) Quantitative visual fields under binocular viewing conditions in primary and consecutive divergent strabismus. Graefes Arch Clin Exp Ophthalmol 237:535-545.

Kimmel DL, Mammo D, Newsome WT (2012) Tracking the eye non-invasively: simultaneous comparison of the scleral search coil and optical tracking techniques in the macaque monkey. Front Behav Neurosci 6:49.

Kiorpes L (1992) Effect of strabismus on the development of vernier acuity and grating acuity in monkeys. Vis Neurosci 9:253-259.

Kiorpes L, Boothe RG, Hendrickson AE, Movshon JA, Eggers HM, Gizzi MS (1987) Effects of early unilateral blur on the macaque's visual system. 1. Behavioral observations. J Neurosci 7:1318-1326.

Kiorpes L, Kiper DC, Movshon JA (1993) Contrast sensitivity and Vernier acuity in amblyopic monkeys. Vision Res 33:2301-2311.

Kiorpes L, Kiper DC, O’Keefe LP, Cavanaugh JR, Movshon JA (1998) Neuronal correlates of amblyopia in the visual cortex of macaque monkeys with experimental strabismus and anisometropia. J Neurosci 18:6411-6424.

Kiper DC, Kiorpes L (1994) Suprathreshold contrast sensitivity in experimentally strabismic monkeys. Vision Res 34:1575-1583.

Kumagami T, Zhang B, Smith EL 3rd, Chino YM (2000) Effect of onset age of strabismus on the binocular responses of neurons in the monkey visual cortex. Invest Ophthalmol Vis Sci 41:948-954.

Levitt JB, Lund JS (2002) The spatial extent over which neurons in macaque striate cortex pool visual signals. Vis Neurosci 19:439-452.

Markov NT, Vezoli J, Chameau P, Falchier A, Quilodran R, Huissoud C, Lamy C, Misery P, Giroud P, Ullman S, Barone P, Dehay C, Knoblauch K, Kennedy H (2014) Anatomy of hierarchy: feedforward and feedback pathways in macaque visual cortex. J Comp Neurol 522:225-259.

Mori T, Matsuura K, Zhang B, Smith EL 3rd, Chino YM (2002) Effects of the duration of early strabismus on the binocular responses of neurons in the monkey visual cortex (V1). Invest Ophthalmol Vis Sci 43:1262-1269.

Pirdankar OH, Das VE (2016) Influence of target parameters on fixation stability in normal and strabismic monkeys. Invest Ophthalmol Vis Sci 57:1087-1095

Poggio GF, Fischer B (1977) Binocular interaction and depth sensitivity in striate and prestriate cortex of behaving rhesus monkey. J Neurophysiol 40:1392-1405

Poggio GF, Gonzalez F, Krause F (1988) Stereoscopic mechanisms in monkey visual cortex: binocular correlation and disparity selectivity. J Neurosci 8:4531-4550.

Prince SJ, Pointon AD, Cumming BG, Parker AJ (2002) Quantitative analysis of the responses of $\mathrm{V} 1$ neurons to horizontal disparity in dynamic random-dot stereograms. J Neurophysiol 87:191-208.

Romeo A, Arall M, Super H (2012) Noise destroys feedback enhanced figureground segmentation but not feedforward figure-ground segmentation. Front Physiol 3:274.

Schmidt KF, Löwel S (2008) Strabismus modifies intrinsic and inter-areal connections in cat area 18. Neuroscience 152:128-137.

Scholl B, Tan AY, Priebe NJ (2013) Strabismus disrupts binocular synaptic integration in primary visual cortex. J Neurosci 33:17108-17122.

Sengpiel F, Blakemore C (1994) Interocular control of neuronal responsiveness in cat visual cortex. Nature 368:847-850.

Sengpiel F, Blakemore C, Kind PC, Harrad R (1994) Interocular suppression in the visual cortex of strabismic cats. J Neurosci 14:6855-6871.

Sengpiel F, Jirmann KU, Vorobyov V, Eysel UT (2006) Strabismic suppression is mediated by inhibitory interactions in the primary visual cortex. Cereb Cortex 16:1750-1758.

Serrano-Pedraza I, Clarke MP, Read JC (2011) Single vision during ocular deviation in intermittent exotropia. Ophthalmic Physiol Opt 31:45-55.

Simmons JB, Turner RS, Horton JC (2020) Long-term labeling of microelectrode tracks with fluorescent latex microspheres. J Neurosci Methods 343:108839.

Smith EL 3rd, Chino YM, Ni J, Cheng H, Crawford ML, Harwerth RS (1997) Residual binocular interactions in the striate cortex of monkeys reared with abnormal binocular vision. J Neurophysiol 78:1353-1362.

Sun LD, Goldberg ME (2016) Corollary discharge and oculomotor proprioception: cortical mechanisms for spatially accurate vision. Annu Rev Vis Sci 2:61-84

Träisk F, Bolzani R, Tallstedt L, Schworm HD, Ygge J (2007) Saccadic eye movement velocity measured with the infrared reflection and search coil eye-tracking systems in patients with thyroid-associated ophthalmopathy. Strabismus 15:173-180.

Tychsen L (1992) Binocular vision. In: Adler's physiology of the eye (Hart WM, ed), Ed 9, pp 773-853. St. Louis: Mosby.

Tychsen L (2005) Can ophthalmologists repair the brain in infantile esotropia? Early surgery, stereopsis, monofixation syndrome, and the legacy of Marshall Parks. J AAPOS 9:510-521.

Tychsen L, Burkhalter A (1997) Nasotemporal asymmetries in V1: ocular dominance columns of infant, adult, and strabismic macaque monkeys. J Comp Neurol 388:32-46.

Tychsen L, Wong AM, Burkhalter A (2004) Paucity of horizontal connections for binocular vision in $\mathrm{V} 1$ of naturally strabismic macaques: cytochrome oxidase compartment specificity. J Comp Neurol $474: 261-275$. 
van der Geest JN, Frens MA (2002) Recording eye movements with videooculography and scleral search coils: a direct comparison of two methods. J Neurosci Methods 114:185-195.

von Gräfe A (1854) Ûber das Doppelsehen nach Schieloperationen und Incongruenz der Netzhaute. Arch f Ophthalmol 1:82-120.

Wan MJ, Chiu H, Shah AS, Hunter DG (2018) Long-term surgical outcomes for large-angle infantile esotropia. Am J Ophthalmol 189: 155-159.

Wiesel TN (1982) Postnatal development of the visual cortex and the influence of environment. Nature 299:583-591.

Wong-Riley MT (1989) Cytochrome oxidase: an endogenous metabolic marker for neuronal activity. Trends Neurosci 12:94-101.
Wong AM, Lueder GT, Burkhalter A, Tychsen L (2000) Anomalous retinal correspondence: neuroanatomic mechanism in strabismic monkeys and clinical findings in strabismic children. J AAPOS 4:168174.

Xing D, Shapley RM, Hawken MJ, Ringach DL (2005) Effect of stimulus size on the dynamics of orientation selectivity in macaque V1. J Neurophysiol 94:799-812.

Zhang B, Bi H, Sakai E, Maruko I, Zheng J, Smith EL 3rd, Chino YM (2005) Rapid plasticity of binocular connections in developing monkey visual cortex (V1). Proc Natl Acad Sci USA 102:9026-9031.

Zipser K, Lamme VA, Schiller PH (1996) Contextual modulation in primary visual cortex. J Neurosci 16:7376-7389. 